\title{
Filosofia da natureza e pensamento estético em Goethe
}

\author{
Wilma Patricia Maas
}

Professora de Literatura Alemã no Dep. de Letras Modernas da FCL-Unesp, Campus de Araraquara (SP) 

O trabalho de Géza von Mólnar, a edição dos estudos kantianos de Goethe sobre a Crítica da faculdade de julgar e a Crítica da razão pura, publicado em 1994, foi decisivo para uma dramática alteração da fortuna crítica sobre a relação de Goethe com a filosofia de Kant. Nesse trabalho, Von Mólnar acompanha as anotações feitas por Goethe em seus exemplares da Crítica da razão pura e da Crítica da faculdade de julgar entre 1790 e 1791, partindo do pressuposto de que as passagens nas quais essas anotações são mais frequentes indicariam exatamente os pontos em que a filosofia kantiana lhe parecera mais significativa. Antes de Mólnar, predominou por muito tempo a ideia de um Goethe claramente não filosófico e mesmo avesso à filosofia e seu método. Ninguém menos do que o próprio Goethe contribui para a criação dessa imagem: é antológica sua afirmação a respeito de não possuir "órgão para a filosofia". Mas também Schiller, indiscutivelmente kantiano, legou à fortuna crítica de Goethe um documento de grande repercussão, no que diz respeito a confirmar a imagem de Goethe como um gênio afilosófico ou antifilosófico:

Em vossa correta intuição tudo se encontra de modo mais completo do que logram conseguir os esforços da análise, e justamente porque o Todo se acha em vós, vossa própria riqueza oculta-se de vossos olhos. [...] A filosofia pode apenas dissecar analiticamente aquilo que lhe é dado, mas o ato de dar em si não é próprio do filósofo analítico, mas sim do gênio $[\ldots]^{2}$ (Schiller a Goethe, 23 de agosto de 1794).

A fortuna crítica dessa ideia de um Goethe genial e afilosófico foi duradoura e produtiva, estendendo-se ao menos até o final do século XX. Posteriormente à publicação dos estudos kantia-

1 |Cf. J. W. von GOETHE. Goethes Werke. Weimar: Hermann Böhlau/Böhlaus Verlag, 1887-1919, 143 v., p. 47 e ss. (Weimarer Ausgabe = WA, 11).

2 "In Ihrer richtigen Intuition liegt alles und weit vollständiger, was die Analysis mühsam sucht, und nur weil es als ein Ganzes in Ihnen liegt, ist Ihnen Ihr eigener Reichthum verborgen; [...] Diese [die Philosophie] kann bloß zergliedern, was ihr gegeben wird, aber das Geben selbst ist nicht die Sache des Analytikers, sondern des Genies." 
nos de Goethe por Mólnar, e certamente influenciada por ela, destaca-se a publicação do ensaio de Wolf von Engelhardt, na revista Athenäum, em 2000, voltado especificamente para a presença de Kant em Der Versuch als Vermittler von Objekt und Subjekt (O ensaio como mediador do objeto e do sujeito). Em 2010, um novo artigo, desta vez da autoria de Angus Nicholls, contribui não apenas para um reconhecimento do pensamento filosófico de Goethe, mas também para a reavaliação de seu trabalho como investigador da natureza. Claro está que, ao final do século XX, tem início uma reavaliação, se não de Goethe como filósofo e cientista ele próprio, certamente de sua perspectiva e abordagem em um e outro campo. Mais do que isso, é possível afirmar que Goethe tomou parte ativa na reelaboração de uma Naturphilosophie, de raízes platônicas.

Mas como se dá, em Goethe, a construção dessa perspectiva da filosofia da natureza? É preciso determo-nos com vagar nessa etapa da produção goethiana (anos 1780-90). Goethe publica Metamorfose das plantas em 1790, mesmo ano em que vem a público a Crítica da faculdade de julgar. Em 1792, é publicada a primeira versão de Versuch als Vermittler $(\mathrm{VaV})$, texto-chave para a investigação da leitura que Goethe faz de Kant. Ali, Goethe tratará do problema da objetividade dos dados obtidos com base na observação dos fenômenos naturais e na passagem da experiência empírica à formação de um juízo. Essa passagem, segundo o Goethe de $\mathrm{VaV}$, tem que ser necessariamente mediatizada pelo que Goethe chamará de "uma experiência superior" (eine Erfahrung höherer Art).

\section{Der Versuch als Vermittler (VaV)}

Tanto em Engelhardt quanto em Nicholls ${ }^{3}$ encontra-se a su- 
gestão de que o ensaio pode ter sido escrito como uma reação a uma resenha anônima dos Beiträge zur Optik, Erstes und Zweites Stück (Contribuições à ótica. Primeira e segunda partes). Na resenha, publicado no Jenaer Allgemeine Literaturzeitung de 28 de janeiro de 1792, o autor anônimo afirma que os resultados obtidos por Goethe e por ele apresentados na primeira parte dos Beiträge poderiam também ser deduzidos com base na teoria de Newton. Segundo essa hipótese, o $V a V$ pode ser lido então na tradição da polêmica goethiana com a Física de Newton. Surpreendentemente, os argumentos de Goethe não têm natureza empírica, mas sim filosófica.

A primeira versão de Der Versuch als Vermittler, ainda sem título, datada de 28 de abril de $1792^{4}$, foi ditada a Schumann, então secretário de Goethe. Em 1798, Goethe envia o manuscrito a Schiller e o intitula "Kautele des Beobachters" (Cautela do observador). Por fim, em 1823, Goethe publica o texto, com pequenas alterações, sob o título de Der Versuch als Vermittler vom Objekt und Subjekt. Engelhardt's chega a sugerir que o título pode ter sido dado por Riemler, secretário de Goethe à época. De fato, o próprio texto goethiano não emprega os termos da maneira com que se articulam no título, e "Subjekt" não aparece nem mesmo uma vez, sendo substituído por "Der Beobachter". Também a função de Vermittler (mediador) atribuída ao experimento ou ensaio (Versuch) só pode ser deduzida indiretamente, uma vez que, segundo o texto goethiano, o acesso ao objeto só pode se dar de maneira "mediata", nunca "imediata".

Goethe trata de estabelecer as condições necessárias para

Goethes Aufsatz im Licht von Kants Vernunftkritik. Athenäum, 2000, p. 9-28. A. NICHOLLS. The Hermeneutics of Scientific Language in Goethe's Critique of Newton. Passagen. 50 Jahre Germanistik an der Monash Universität, 2010, p. 510-58.

4 Wolf von Engelhardt apresenta uma minuciosa investigação sobre as circunstâncias de origem do texto, seguida de uma também minuciosa comparação entre o texto do ensaio e as anotações do prório Goethe sobre a edição da Primeira Crítica, da qual nos valemos aqui: W. von ENGELHARDT. "Der Versuch..., op. cit., p. 9-28.

${ }_{5}$ Id., ibid., p. 9. 
uma investigação objetiva dos fenômenos naturais. Estas, além do equipamento adequado, incluem uma capacidade do investigador que o torne apto a não se deixar enganar por meio de um julgamento apressado dos resultados obtidos. Goethe atribui essa tendência do observador ao autoengano ou autoilusão à elaboração imediata de um juízo com base na percepção empírica. Esta leva a uma "representação" (Vorstellung) subjetiva e errônea, prejudicial porque guiada pela organização mental de cada observador:

O homem se satisfaz mais com a representação do que com a própria coisa, ou dito de outro modo: o homem se satisfaz com algo na mesma medida em que o representa para si mesmo. Um tal objeto deve adequar-se a sua maneira de perceber o mundo, e, por mais que o observador seja capaz de elevar e apurar sua capacidade de representação em relação ao senso comum, o processo não passa de uma tentativa de atribuir uma determinada relação comum a muitos objetos diferentes, relação essa que, no limite, tais objetos não mantêm entre si; daí a tendência à constituição de hipóteses, teorias, terminologias e sistemas, que não podemos desaprovar de todo, porque derivam necessariamente da organização de nosso próprio $\operatorname{ser}^{6}$.

O termo "Vorstellungsarten", que aparece nos escritos de Goethe sobre as ciências naturais apenas a partir de 1790 (ao final do ensaio Versuch die Metamorphose der Pflanzen zu erklären), evoca, segundo Engelhardt, a tese fundamental de Kant, segundo a qual "a nossa representação das coisas como nos são dadas", guia-se "não por estas como coisas em si mesmas, mas que es-

6 "Der Mensch erfreut sich nämlich mehr an der Vorstellung als an der Sache, oder wir müssen sagen:Der Mensch erfreut sich nur einer Sache, in so fern er sich dieselbe vorstellt; sie muß in seine Sinnesart passen, und er mag seine Vorstellungsart noch so hoch über die gemeine erheben, noch so sehr reinigen, so bleibt sie doch gewöhnlich nur ein Versuch, viele Gegenstände in ein gewisses fäßliches Verhältniß zu bringen, das sie, streng genommen, unter einander nicht haben; daher die Neigung zu Hypothesen, zu Theorien, Terminologien und Systemen, die wir nich mißbilligen können, weil sie aus der Organisation unseres Wesens nothwendig entspringen" (J. W. von GOETHE. Goethes.., op. cit., WA, 11, p. 29, grifos meus). 
tes objetos, como fenômenos muito antes se guia[e]m pelo nosso modo de representação $[\ldots]$...7.

Seguindo ainda o raciocínio expresso na Primeira Crítica, precisamos da filosofia crítica para podermos reconhecer "os passos em falso da capacidade de julgar (lapsus judicii)", pondo-os sob o abrigo dos "poucos conceitos puros do entendimento". $\mathrm{O}$ texto de $\mathrm{VaV}$ organiza-se ao redor desse princípio. Isso significa que, em 1792, Goethe, já adiantado em seus estudos da Crítica do juízo e da Crítica da razão pura, está em condições de problematizar seu próprio método de investigação científica, baseado, até então, no empirismo mais evidente. O texto de $\mathrm{VaV}$ organiza-se em torno de três termos fundamentais: e/Experiência (Erfahrung), representação (Vorstellung) e ensaio, tentativa ou experimento (Versuch).

O termo "experiência" aparece logo às primeiras páginas, em um registro algo surpreendente em se tratando do Goethe observador científico:

Ninguém nega que a experiência exerce e deve mesmo exercer a maior influência em tudo o que o homem empreende, assim como também na doutrina da natureza; tampouco o negamos quando deixamos de atribuir às forças da alma, nas quais tais experiências são reunidas e organizadas, seu alto e independente poder criativo 9 .

No que diz respeito à retórica do trecho, afirmar que "ninguém nega que a experiência tem a maior influência na doutrina da Natureza" equivale quase a reconhecer que esse é um princí-

7 I. KANT. Crítica da razão pura. Trad. de V. Rohden, U. B. Moosburger. São Paulo: Nova Cultural, 1999, p. 40.

8 Id., ibid., p. 143.

9 "Daß die Erfahrung, wie in allem was der Mensch unternimmt, so auch in der Naturlehre, von der ich gegenwärtig vorzüglich spreche, den größten Einfluß habe und haben solle, wird niemand läugnen, so wenig als man den Seelenkräften, in welchen diese Erfahrungen aufgefaßt, zusammengenommen, geordnet und ausgebildet werden, ihre hohe und gleichsam schöpferisch unabhängige Kraft absprechen wird” (J. W. von GOETHE. Goethes..., op. cit., WA, 11, p. 24). 
pio que pode não levar sempre ao conhecimento. Ao longo do texto, justamente esse princípio será problematizado. Goethe desenvolverá uma argumentação, de base nitidamente kantiana, que concluirá pela necessidade de ascendermos a um nível superior do conhecimento. Este só pode se dar de maneira mediata:

Eu afirmei anteriormente que considero prejudicial o emprego imediato de um experimento a fim de comprovar uma hipótese; com isso dei a conhecer o fato de que considero útil o emprego mediato de tal experimento, e, uma vez que tudo depende desse ponto, é necessário explicá-lo com clareza ${ }^{10}$.

Goethe adverte claramente quanto aos perigos de um julgamento apressado, motivado pela percepção empírica imediata, por meio dos "sentidos aguçados e alertas" ", que podem levar mesmo o observador mais preparado a dar passos apressados, que o libertem dos limites traçados por uma "investigação penosa e cansativa". A aplicação dos resultados de um experimento em direção a sua comprovação não pode, portanto, ser imediata.

Mas o que deve, então, conduzir essa passagem da experiência imediata à formação de um juízo?

Trata-se de uma "experiência mais elevada [eine Erfahrung höherer Art]”, dirá Goethe, capaz de conter em si a soma de todos os experimentos isolados. Trata-se de uma Experiência ao mesmo tempo ideal e plural, como uma fórmula matemática:

Uma tal Experiência, que se constitui de muitas outras, é claramente uma experiência de um tipo mais elevado. Ela representa a fórmula sob

10 "Ich habe vorhin gesagt, daß ich die unmittelbare Anwendung eines Versuchs zum Beweis irgend einer Hypothese für schädlich halte, und habe dadurch zu erkennen gegeben, daß ich eine mittelbare Anwendung derselben für nützlich ansehe, und da auf diesen Punct alles ankommt, so ist es nöthig sich deutlich zu erklären" (id., ibid., WA, 11, p. 31).

11 Id., ibid., WA, 11, p. 24. 
a qual um número incontável de outros exemplos se deixam expressar ${ }^{12}$ $[\ldots]$.

Cada fenômeno isolado está, de fato, associado a um número incontável de outros fenômenos, associação essa que escapa a nossa mera percepção empírica. É apenas por meio dessa Experiência mais elevada que poderemos vivenciar a verdadeira natureza dos objetos de investigação. Em Kant, a Experiência mais elevada corresponde à síntese operada pelo entendimento (Verstand), que produz conhecimento com base na multiplicidade do conhecimento empírico:

[...] A espontaneidade de nosso pensamento exige que tal múltiplo seja primeiro e de certo modo perpassado, acolhido e ligado para que se faça disso um conhecimento. Denomino essa ação síntese. Por síntese entendo, no sentido mais amplo, a ação de acrescentar diversas representações umas às outras e de conceber sua multiplicidade num conhecimento ${ }^{13}$.

Goethe está agindo ainda de acordo com a síntese kantiana quando propõe sua definição de experimento (Versuch):

Chamamos de experimento [Versuch] a repetição intencional das experiências feitas anteriormente por nós mesmos ou por outros, causando portanto a reconstituição dos fenômenos que ocorrem em parte casualmente e em parte por meio de artifícios. O valor de um experimento reside especialmente no fato de que ele [...] pode ser realizado a cada vez que as condições necessárias se encontrem associadas. Certamente admiramos o entendimento humano quando vemos, ainda que apenas

12 "Eine solche Erfahrung, die aus mehreren andern besteht, ist offenbar Von einer höherer Art. Sie stellt die Formel vor, unter welcher unzählige einzelne Rechnungsexempel ausgedrückt werden [...]" (id., ibid., WA, 11, p. 33)

13 "Allein die Spontaneität unseres Denkens erfordert es, daß dieses Mannigfaltige zuerst auf gewisse Weise durchgegangen, aufgenommen und verbunden werde, um daraus eine Erkenntnis zu machen. Diese Handlung nenne ich Synthesis. Ich verstehe aber unter Synthesis in der allgemeinsten Bedeutung die Handlung, verschiedene Vorstellungen zu einander hinzuzuthun und ihre Mannigfaltigkeit in einer Erkenntniß zu begreifen” (I. KANT. Crítica da razão..., op. cit., p. 107, KrV B103; grifo meu). 
superficialmente, as combinações que ele realizou para chegar a essa finalidade e contemplamos as máquinas criadas para tanto $[\ldots]^{14}$.

Entende-se, daí, que o experimento ou ensaio é uma espécie de "unidade mínima" constituinte da Experiência, que pode ser novamente realizado, isto é, repetido, uma vez que se estabeleçam as condições, naturais ou artificiais, necessárias para sua realização. No entanto, adverte Goethe, "cada experiência que fazemos, cada experimento por meio do qual a realizamos novamente, é, na verdade, uma parte isolada de nosso conhecimento; por meio da repetição frequente de cada experimento tornamos conhecimento isolado em certeza ${ }^{15}$. Duas páginas adiante, Goethe usará outros termos em lugar de repetição: A multiplicação (Vermannichfaltigung) de um único experimento é, portanto, a tarefa apropriada ao pesquisador da natureza ${ }^{16}$. "Multiplicação", ou "diversificação", porém, são termos insuficientes para traduzir o sentido de Vermannigfaltigung. Trata-se de atribuir ao experimento riqueza e variedade de formas, reproduzir suas etapas em diferentes versões, de modo que cada uma delas contribua para a constituição de uma Experiência maior, composta idealmente pelas diferentes realizações do mesmo experimento ${ }^{17}$.

14 "Der Werth eines Versuchs besteht vorzüglich darin, daß er [...] wieder hervorgebracht werden könne, so oft sich die bedingten Umstände vereinigen lassen. Wir bewundern mit Recht den menschlichen Verstand, wenn wir auch nur obenhin die Combinationen ansehen, die er zu diesem Endzwecke gemacht hat, und die Maschinen betrachten, die dazu erfunden worden sind [...]" (J. W. von GOETHE. Goethes..., op. cit., WA, 11, p. 26-7).

15 "Eine jede Erfahrung die wir machen, ein jeder Versuch durch den wir sie wiederholen, ist eigentlich ein isolirter Theil unserer Erkenntni ; durch öftere Wiederholung bringen wir diese isolirte Kenntni zur Gewi heit" (J. W. von GOETHE. Goethes..., op. cit., WA, 11, p. 28-9).

16 "Die Vermannichfaltigung eines jeden einzelnen Versuches ist also die eigentliche Pflicht eines Naturforschers" (id., ibid., WA, 11, p. 32; grifo do autor).

17 Como afirma o próprio Goethe ao final do ensaio, seus Beiträge zur Optik são o mais claro exemplo desse método. Ali, as experiências com o prisma são repetidas, mas ao mesmo tempo enriquecidas com variações minuciosas, como a inversão da posição das superfícies branca e preta dos cartões que refletem os raios de luz filtrados pelo prisma de vidro. Diz Goethe: "Nas duas primeiras partes das minhas Contribuições à ótica, procurei alinhar uma sequência de experimentos que determinam os limites 
Como unidades mínimas que são, cada experimento singular pode ser associado a outro, por meio da nossa observação. No entanto, é exatamente essa associação que pode ser perigosa para a objetividade do julgamento, pois a mera associação de um experimento a outro não prova nada e, em geral, é enganosa, mero produto de nossas representações.

Ouso mesmo afirmar que um experimento, até mesmo muitos experimentos em cadeia não provam nada, que nada é mais perigoso do que querer ratificar qualquer princípio por meio de experimentos, e que os maiores equívocos surgem do fato que a maioria de nós deixa de perceber a insuficiência desse método ${ }^{18}$.

O risco de deixar-se convencer por um julgamento errado quanto à natureza das coisas reside justamente no passo que vai da experiência ao juízo. Esse é o momento em que o observador pode ser assaltado por uma série de "inimigos interiores", que contribuirão para a ilusão e o engano:

Todo o cuidado é pouco diante dos riscos de tirarmos conclusões muito rapidamente com base nos experimentos; pois é na passagem da experiência ao julgamento, do conhecimento à aplicação que todos os inimigos interiores do homem estão à espreita: a imaginação, a impaciência, a pressa, a satisfação consigo mesmo, a teimosia, o modo de pensar, os pré-julgamentos, o comodismo, a leviandade, a instabilidade de ânimo,

uns aos outros e mesmo aludem imediatamente uns aos outros; quando se conhece a todos eles muito bem e deles se tem uma perspectiva ampla, pode-se dizer que eles constituem em certa medida Um Experimento, representam apenas Uma Experiência , sob os mais variados pontos de vista (id., ibid., WA, 11, p. 33) ("Ich habe in den zwei ersten Stücken meiner optischen Beiträge eine solche Reihe von Versuchen aufzustellen gesucht, die zunächst an einander gränzen und sich unmittelbar berühren, ja, wenn man sie alle genau kennt und übersieht, gleichsam nur Einen Versuch ausmachen, nur Eine Erfahrung unter den mannichfaltigsten Ansichten darstellen").

18 "Ich wage nämlich zu behaupten: daß Ein Versuch, ja mehrere Versuche in Verbindung nichts beweisen, ja daß nichts gefährlicher sei als irgend einen Satz unmittelbar durch Versuche bestätigen zu wollen, und daß die größten Irrthümer eben dadurch entstanden sind, daß man die Gefahr und die Unzulänglichkeit dieser Methode nicht eingesehen" (id., ibid., WA, 11, p. 28). 
como quer que se nomeie o bando todo com suas consequências, todos estão por trás e observam imperceptivelmente tanto o homem do mundo quanto o observador tranquilo e aparentemente a salvo das paixões mundanas ${ }^{19}$.

É, pois, unicamente por meio da síntese filosófica, capaz de unificar, em uma fórmula ideal, toda a diversidade empírica, que se pode atingir o conhecimento das coisas. Um conjunto de experimentos únicos associados constituirá, portanto, uma diversidade que só poderá ser conhecida idealmente, por meio da síntese. Ou seja, o conhecimento só pode ser mediato, nunca imediato.

\section{Planta Primordial e simbolismo}

No famoso relato do encontro com Schiller, "Glückliches Ereignis" (Acontecimento feliz), Goethe dá a conhecer, sob a perspectiva da dinâmica de sua relação intelectual com Schiller, o exemplo mais claro de sua concepção da Experiência mais elevada. Ao criticar a palestra sobre botânica a que ambos haviam acabado de assistir na Sociedade Científica de Jena, Goethe e Schiller concordam que o palestrante optara por um método de cunho exclusivamente analítico, ao isolar as partes dos organismos naturais para classificá-las, excluindo assim a dinâmica própria aos objetos naturais. Ao longo da conversa, Goethe tenta explicar a Schiller sua teoria da metamorfose das plantas, desenhando então a "Planta Primordial" (Urpflanze), para ilustrar,

19 "Man kann sich daher nicht genug in Acht nehmen, aus Versuchen nicht zu geschwind zu folgern: denn bei’m Übergang von der Erfahrung zum Urtheil, von der Erkenntniß zur Anwendung ist es, wo dem Menschen gleichsam wie an einem Passe alle seine inneren Feinde auflauern, Einbildungskraft, Ungeduld, Vorschnelligkeit, Selbstzufriedenheit, Streifheit, Gedankenform, vorgefaßte Meinung, Bequemlichkeit, Leichtsinn, Veränderlichkeit, und wie die ganze Schaar mit ihrem Gefolge heißen mag, alle liegen hier im Hinterhalte und überwältigen unversehens sowohl den handelnden Weltmann als auch den stillen, vor allen Leidenschaften gesichert scheinenden Beobachter" (J. W. von GOETHE. Goethes..., op. cit., WA, 11, p. 27-8). 
como sugere Eckart Förster ${ }^{20}$, sua hipótese de forças atuantes a partir do todo em direção às partes, nas quais o Todo pode ser intuído. Schiller teria replicado que tal exemplo não derivava de uma observação da experiência, tratava-se antes de uma "ideia". Aquilo que Schiller rejeita como mero produto da imaginação, Goethe reconhecerá como a percepção, no objeto particular, de algo que excede a soma de cada elemento isolado. Em maio de 1787, Goethe escrevera a Charlotte von Stein e a Herder, de Nápoles, o que entende por Planta Primordial:

Sob este céu é possível fazer as mais belas observações. Diga-lhe [a Herder] que já não tenho mais dúvidas, que claramente descobri onde se encontra o cerne das coisas, diga-lhe que agora sou capaz de contemplar tudo o mais no Todo e que apenas alguns pontos precisam ainda de melhor definição. A Planta Primordial será a criação mais prodigiosa do universo, pela qual a própria Natureza deverá invejar-me. Com esse modelo e essa chave, pode-se descobrir um número infinito de plantas, em uma série consequente. Isso quer dizer que, mesmo que não existam, sua existência seria certamente possível, não como sombra e aparência artística ou poética, mas sim dotadas de uma verdade e necessidade internas ${ }^{21}$.

Percebe-se, desse modo, que a mediatização da experiência, defendida por Goethe no ensaio de 1792, já se encontrava em germe durante a viagem à Itália, ocasião em que Goethe toma contato com a diversidade da flora mediterrânea. Assim como a Experiência mais elevada, a Planta Primordial, em seu caráter

20 E. FÖRSTER, 2001.

21 "Unter diesem Himmel kann man die schönsten Beobachtungen machen. Sage ihm daß ich den Hauptpunckt wo der Keim stickt ganz klar und zweifellos entdeckt habe, daß ich alles übrige auch schon im Ganzen übersehe und nur noch einige Punckte bestimmter werden müssen. Die Urpflanze wird das wunderlichste Geschöpf von der Welt über welches mich die Natur selbst beneiden soll. Mit diesem Modell und dem Schlüßel dazu, kann man alsdann noch Pflanzen ins unendliche erfinden, die konsequent seyn müßen, das heißt: die, wenn sie auch nicht existiren, doch existiren könnten und nicht etwa mahlerische oder dichterische Schatten und Scheine sind, sondern eine innerliche Wahrheit und Nothwendigkeit haben" (J. W. von GOETHE. Goethes..., op. cit., WA, IV, p. 232-3; grifo meu). 
ideal, é "o modelo e a chave" de um número infinito de plantas que poderiam existir, ainda que não existam. A Experiência mais elevada, assim como a Planta Primordial, transita entre o sensível e o suprasensível, confirmando assim uma percepção do mundo voltada à investigação dos limites do conhecimento exclusivamente empírico.

O reconhecimento desses limites, expresso na noção da Planta Primordial, levará Goethe, a partir de então, a buscar uma possibilidade de mediação entre a observação direta do fenômeno e a emissão de juízos sobre aquele por meio da criação de um simbolismo (eine Symbolik). Quando, na carta a Charlotte von Stein de 1787 , Goethe afirma que a própria natureza o invejará pela criação da Urpflanze, aquilo que parece ser mero recurso estilístico, um torneio de frase, aponta para nada menos do que a constituição do que será mais tarde o método de investigação da natureza defendido por Goethe: a necessidade de um "künstlicher Vortrag", ou seja, de uma possibilidade artificial e artificiosa de exposição do conhecimento do objeto, distinta do acesso oferecido imediatamente pela experiência. Goethe chega a esboçar, em uma breve nota, publicada sob o título de "Problemas", encaminhada em 1823 ao botânico Ernst Meyer, a demanda por um tipo de linguagem ou de simbolismo capaz de abarcar o que lhe parecera, em princípio, o caráter contraditório de seu próprio método morfológico:

A ideia de metamorfose é digna de grande consideração, mas é também ao mesmo tempo uma dádiva altamente perigosa. Ela conduz ao informe, destrói o conhecimento, dissolve-o. Ela é como a força centrífuga e perder-se-ia no infinito, caso não se lhe interpusesse um contrapeso. Refiro-me com isso ao impulso de especificação, a teimosa persistência das coisas uma vez tornadas realidade. Uma força centrípeta, cujos princípios mais profundos não podem ser alterados por qualquer fator externo. [...] Seria preciso dar lugar a um tipo de discurso artificial e artificioso, seria preciso construir um simbolismo! Mas quem seria capaz de criá-lo? Quem 
depois o reconheceria? ${ }^{22}$.

Em ambos os momentos, na carta de 1787 e na nota escrita 36 anos depois, Goethe alude ao mesmo recurso que fora nomeado como a construção de uma Experiência mais elevada, no texto de $\mathrm{VaV}$. A persistência da tópica leva-nos a concluir por sua legitimidade no pensamento científico do autor. Goethe defende a construção, na razão, de uma linguagem elaborada com base na experiência e no fenômeno, mas que não se confunde com estes. Nomeada respectivamente "Urphänomen", "Erfahrung höherer Art" e, por fim, "Symbolik", essa tal construção artificial tem a tarefa de prover a razão dos conceitos que lhe faltam, no caso dos objetos e fenômenos naturais. Essa mesma construção está nitidamente associada ao pensamento teleológico, tanto em Goethe quanto em Kant.

\section{A conformidade a fins e o programa estético de Goethe}

Kant, na segunda parte da Crítica da faculdade de julgar, intitulada "Crítica da faculdade de juízo teleológica", distinguirá entre aqueles objetos cuja finalidade é meramente mecânica daqueles providos de uma finalidade intrínseca:

Para perceber que uma coisa somente é possível como fim, isto é, para devermos procurar a causalidade da sua origem não no mecanismo da natureza, mas numa causa cuja faculdade de atuar é determinada por conceitos, torna-se necessário que a respectiva forma não seja possível

22 "Die Idee der Metamorphose ist eine höchst ehrwürdige aber zugleich höchst gefährliche Gabe von oben. Sie führt in's Formlose, zerstört das Wissen, lös't es auf. Sie ist gleich der vis centrifuga und würde sich in's Unendliche verlieren, wäre ihr nicht ein Gegengewicht zugegeben: ich meine den Specificationstrieb, das zähe Beharrlichkeitsvermögen dessen was einmal zur Wirklichkeit gekommen. Eine vis centripeta, welcher in ihrem tiefsten Grunde keine Äußerlichkeit etwas anhaben kann. [...] Wir mü ten einen künstlichen Vortrag eintreten lassen. Eine Symbolik wäre aufzustellen! Wer aber soll sie leisten? Wer das Geleistete annerkennen?" (J. W. von GOETHE. Goethes..., op. cit., WA, 7, p. 75-6, grifo meu). 
segundo simples leis da natureza, isto é, aquelas leis que podem ser por nós conhecidas somente através do entendimento, aplicado aos objetos dos sentidos. Pelo contrário, é exigido que mesmo o seu conhecimento empírico, nas suas causas e efeitos, pressuponha conceitos da razão $0^{23}$.

Caberá, portanto, à razão prover os conceitos que possibilitem reconhecer a forma necessária dos fins. A causalidade ali identificada é a capacidade de atuar segundo fins, e representar um objeto como possível apenas por meio de uma tal faculdade é representá-lo como possível apenas enquanto fim. No caso dos objetos naturais, ao contrário das figuras geométricas, cujos conceitos já se encontram dados na razão², é preciso construir o conceito capaz de evidenciar a "necessidade" da forma, ou do propósito intrínseco.

Para que se possa, entretanto, ajuizar "aquilo que se conhece como produto natural, como se fosse fim, por conseguinte, como fim natural $[. .$.$] algo mais se deve exigir" { }^{25}$. A prova definitiva de que um objeto natural deve ser considerado como provido de um fim intrínseco é que ele seja "causa e efeito de si mesmo, uma vez que isso envolve uma causalidade tal, que não pode ser associada ao mero conceito de natureza", sem que consideremos a natureza

23 I. KANT. Crítica da faculdade do juízo. Trad. de V. Rohden, A. Marques. 2. ed. Rio de Janeiro: Forense Universitária, 2002, p. 212, grifo meu.

24 "Se alguém, numa terra que lhe pareça desabitada, percebesse desenhada na areia uma figura geométrica, por exemplo, um hexágono regular, então quando muito a sua reflexão captaria por meio da razão, na medida em que trabalhasse, num conceito daquela mesma figura, a unidade do princípio de produção da mesma, ainda que de modo obscuro e assim não ajuizaria, segundo esta unidade, a areia, o vizinho mar, os ventos ou também os animais com as pegadas que ele conhece, ou ainda qualquer coisa desprovida de razão, como um fundamento de possibilidade de uma tal figura. A razão é que a contingência de um acordo dessa figura com um tal conceito, que somente é dado na razão, lhe pareceria tão infinitamente grande que seria indiferente que, nesse caso, houvesse ou não qualquer lei da natureza. Por conseguinte, também nenhuma causa na natureza, atuante de modo simplesmente mecânico, mas somente o conceito de um tal objeto como conceito - o qual somente a razão pode dar e com o qual pode comparar o objeto - poderá conter a causalidade para um tal efeito, e assim esse pode ser considerado inteiramente como fim, mas não como fim natural, isto é, como produto da arte (vestigium hominis video)" (id., ibid., grifo meu).

25 Id., ibid., p. 213. 
como agindo a partir de um propósito. O exemplo oferecido por Kant é o da árvore, que gera outra árvore, segundo uma conhecida lei natural. Mas o fato de que seu produto pertence à mesma espécie significa que

a árvore produz-se a si mesma segundo a espécie na qual ela se conserva firmemente como espécie, quer como efeito, quer ainda como causa, produzida incessantemente a partir de si mesma e do mesmo modo produzindo-se muitas vezes a si mesma ${ }^{26}$.

A definição do fim natural é reforçada ainda, no mesmo exemplo, pelo fato de que o crescimento da árvore individual deve ser entendido em um sentido que o distingue completamente de qualquer aumento de tamanho que se dê de acordo com leis mecânicas. A qualidade generativa desse crescimento pode ser vista na própria matéria-prima que compõe a árvore, matéria essa que se diferencia dos meros nutrientes absorvidos. Essa qualidade, que o mecanismo exterior à planta não pode suprir, não pode se obtida pelo engenho humano:

toda a arte fica infinitamente longe dela [da originalidade das forças presentes nos seres naturais] se pretender reconstituir aqueles produtos do reino vegetal a partir dos elementos que obtém através da divisão destes ou a partir das substâncias que a natureza fornece para sua alimentação ${ }^{27}$.

Para que algo possa ser considerado como fim é preciso ainda que suas partes "somente sejam possíveis mediante a sua relação ao todo" ${ }^{28}$. Isso significa que, uma vez que o objeto é considerado como dotado de propósito ou fim, é

apreendido sob um conceito ou uma ideia que tem de determinar a prio- 
ri tudo o que nele deve estar contido. Mas, na medida em que uma coisa é somente pensada como possível deste modo, é meramente uma obra de arte, isto é, o produto de uma causa racional distinta da matéria (das partes) daquela mesma obra, cuja causalidade (na constituição e na ligação das partes) é determinada através da sua ideia de um todo tornado assim possível (por conseguinte não mediante a natureza fora de si) ${ }^{29}$.

Desse modo, Kant atribuirá a "perfeição natural interna [innere Naturvollkommenheit]" apenas aos objetos possiveis enquanto fins naturais. Ainda que a beleza da natureza possa ser designada como um análogo da arte, uma vez que ela é atribuída aos objetos somente por causa das formas superficiais, a perfeição interna ou intrínseca não pode ser pensada e explicada segundo nenhuma analogia, "nem mesmo através de uma analogia perfeitamente adequada à arte humana, já que nós próprios pertencemos à natureza no mais amplo sentido" $3^{\circ}$.

Aqui, Goethe afasta-se ao mesmo tempo em que se aproxima de Kant, ao elaborar seu conceito de obra de arte simbólica. Para Goethe, o artista ou artífice é a alma capaz de fazer emergir o Belo, ou seja, a força produtiva é do artista, é afeto, e age em colaboração com a natureza. No texto de 1797 "Sobre os objetos das artes plásticas", Goethe propõe inicialmente uma tipologia dos objetos artísticos, divididos entre "naturais", "ideais" e objetos "que não seriam em si e para si compreensíveis ou interessantes" ${ }^{31}$, mas que só podem ser apreciados quando incluídos em uma sequência, visual ou narrativa. Como naturais, Goethe classifica aqueles objetos que representam "coisas conhecidas, comuns, ordinárias, tais como são $[\ldots]$ " $3^{2}$, mesmo quando elevados ao estatuto de um todo artístico. Produzidos pela natureza, tais objetos são elevados

29 I. KANT. Crítica da faculdade...

30 Id., ibid., p. 218.

31 J. W. von GOETHE. Escritos sobre arte. Trad. de M. A. Werle. 2. ed. São Paulo:

Humanitas/Imprensa Oficial, 2008, p. 84. 32 Id., ibid., p. 83. 
a objetos artísticos pelo trabalho mecânico do artista (cf. a força de caráter mecânico que Kant atribui aos objetos [naturais] desprovidos de propósito intrínseco). Já os objetos ideais (idealisch) apresentam-se ao artista "como um objeto perfeita e completamente construído" (vollkommen gebildeter Gegenstande). Distinguem-se dos objetos naturais ainda porque são "produzidos pelo espírito do homem, na mais íntima relação com a Natureza”33. Pode-se entender aqui a definição goethiana de objeto ideal como próxima do que Kant considera como um objeto dotado de propósito intrínseco. Entretanto, ao passo que Kant reconhece que a intervenção da razão humana, ao criar o conceito ou Ideia capaz de determinar a existência do objeto em sua perfectibilidade, transforma-o em "mero produto da arte", Goethe, ao contrário, privilegia exatamente o momento de intervenção da alma humana na elaboração do conceito ou Ideia que determinará o objeto em suas partes, a partir do Todo. Voltamos aqui à necessidade reconhecida por Goethe da elaboração racional de uma exposição artificiosa/artificial, um "künstlicher Vortrag", procedimento associado inicialmente à morfologia das plantas, mas que reaparece também em seu discurso sobre a arte. Nesse caso, a noção goethiana de símbolo deverá portar as mesmas caracterísiticas capazes de conter o processo sucessivo, dinâmico e polissêmico que Goethe divisara já na Planta Primordial.

Ao final da classificação dos objetos artísticos, Goethe propõe, de acordo com a intensificação da função do afeto criador, o deslocamento final da perspectiva com base nos objetos em direção a uma concepção da arte como resultado da força produtiva do artista, do tratamento dado ao objeto por seu espírito, e não da mera capacidade de imitação:

Se em todas as elaborações artísticas o objeto [Gegenstand] nunca pode

33 J. W. von GOETHE. Goethes.., op. cit., WA, 47, p. 92, grifo meu. 
ser considerado isoladamente, mas na medida em que é manejado, podemos contudo dizer dos três gêneros agora descritos que eles são particularmente considerados em relação ao objeto [Objekt]. Nos gêneros que se seguem será mais considerado o tratamento e o espírito daquele que trata do objeto $[\ldots]^{34}$.

Pode-se reconhecer aí a virada copernicana do autor, que desloca a determinação da obra de arte do campo do objeto para o campo da produção, ou seja, do espírito que cria. O simbólico é resultada assim do tratamento dado ao objeto, ou, melhor ainda, da qualidade do sentimento que afeta o artista, um "sentimento profundo", que, coincidindo com "os melhores e supremos objetos $[\ldots]$, no melhor dos casos, os fará simbólicos"35. A dificuldade inicial de compreendermos o que Goethe quer dizer quando distingue o símbolo da alegoria em proveito do primeiro pode ser explicada pela exclusão do traço analógico e discursivo. O símbolo para Goethe é a expressão quase mística de um processo simultâneo e polissêmico, de caráter não discursivo, que desdenha da comparação e da narratividade, semas que constituem a alegoria. Em lugar destes, o símbolo goethiano, artístico e artificial, expressará a simultaneidade dos processos e a concentração das forças antitéticas que atuam na constituição dos processos naturais.

O termo "simbólico" tem em Goethe, portanto, um sentido que declina de qualquer analogia. Não se trata de um signo em lugar de outro, de uma metáfora ou comparação. Simbólico é, para Goethe, o objeto que "parece existir meramente por si mesmo", mantendo-se, ainda assim, profundamente significativo. Goethe reconhecerá no momento da construção racional do conceito (o discurso artificioso/artístico) o momento decisivo da constituição do Belo (artístico). Sua concepção de símbolo, a nosso ver, nada mais é do que o reconhecimento da necessidade da construção,

34 J. W. von GOETHE. Escritos..., op. cit., p. 84-5, grifo meu. 35 Id., ibid., p. 85. 
na razão, da Ideia que imprime direção e organicidade às partes. Assim como o objeto (natural) dotado de propósito intrínseco, o objeto simbólico goethiano é "um produto em que tudo é fim e reciprocamente meio. Nele nada é em vão, sem fim ou atribuível a um mecanismo natural cego" ${ }^{36}$. Goethe recupera, para o objeto artístico, o caráter autotélico dos objetos naturais dotados de finalidade intrínseca.

\section{Bibliografia}

ENGELHARDT, W. von. "Der Versuch als Vermittler von Objekt und Subjekt”: Goethes Aufsatz im Licht von Kants Vernunftkritik. Athenäum, 2000, p. 9-28.

FÖRSTER, E. 2001.

GOETHE, J. W. von. Goethes Werke. Weimar: Hermann Böhlau/Böhlaus Verlag, 1887-1919. 143 v. Ed. por ordem da grãduquesa S. von Sachsen (Weimarer Ausgabe =WA).

. Escritos sobre arte. Trad. de M. A. Werle. 2. ed. São Paulo: Humanitas/Imprensa Oficial, 2008. (Col. A Formação da Estética).

KANT, I. Crítica da razão pura. Trad. de V. Rohden, U. B. Moosburger. São Paulo: Nova Cultural, 1999 (Col. Os Pensadores). Crítica da faculdade do juízo. Trad. de V. Rohden, A. Marques. 2. ed. Rio de Janeiro: Forense Universitária, 2002.

MÓLNAR, G. von. Goethes Studium der Kritik der Urteilskraft: Eine Zusammenstellungnach den Eintragungen in seinem Handexemplar. Goethe Yearbook, v. 2, p. 137-222, 1984. 
MÓLNAR, G. von. Goethes Kantstudien. Weimar: Hermann Böhlaus Nachfolger, 1994 .

NICHOLLS, A. The Hermeneutics of Scientific Language in Goethe's Critique of Newton. Passagen. 50 Jahre Germanistik an der Monash Universität, 2010, p. 510-58.

SCHILLER, F. Briefwechsel zwischen Schiller und Goethe. v. 1. 4. ed. Stuttgart: J. G. Cotta'schen Buchhandlung, 1881. Disponível em: <http://www.wissen-im-netz.info/literatur/goethe/ briefe/schiller/1/004.htm>. Acesso em: ${ }^{\circ}$ fev. 2012. 